\title{
Tumor Infiltrating Lymphocyte Therapy
}

National Cancer Institute

\section{Source}

National Cancer Institute. Tumor Infiltrating Lymphocyte Therapy. NCI Thesaurus. Code C15524.

A form of adoptive cell transfer in which lymphocytes are isolated from a patient's tumor, grown in vitro, and then infused into the patient in combination with interleukin 2. 